\title{
Biochemical evidence for energy-independent flippase activity in bovine epididymal sperm membranes: an insight into membrane biogenesis
}

\author{
Archita Rajasekharan, Vincent Gerard Francis and Sathyanarayana N Gummadi \\ Applied Industrial Microbiology Laboratory, Department of Biotechnology, Indian Institute of Technology Madras, \\ Chennai 600 036, India \\ Correspondence should be addressed to S N Gummadi; Email: gummadi@iitm.ac.in
}

\begin{abstract}
During the maturation process spermatozoa undergo a series of changes in their lateral and horizontal lipid profiles. However, lipid metabolism in spermatozoa is not clearly understood for two reasons: i) the mature spermatozoa are devoid of endoplasmic reticulum, which is the major site of phospholipid (PL) synthesis in somatic cells, and ii) studies have been superficial due to the difficulty in culturing spermatozoa. We hypothesize that spermatozoa contain biogenic membrane flippases since immense changes in lipids occur during spermatogenic differentiation. To test this, we isolated spermatozoa from bovine epididymides and reconstituted the detergent extract of sperm membranes into proteoliposomes. In vitro assays showed that proteoliposomes reconstituted with sperm membrane proteins exhibit ATP-independent flip-flop movement of phosphatidylcholine (PC), phosphatidylserine, and phosphatidylglycerol. Half-life time of PC flipping was found to be $\sim 3.2 \pm 1 \mathrm{~min}$ for whole sperm membrane, which otherwise would have taken $\sim 11-12 \mathrm{~h}$ in the absence of protein. Further biochemical studies confirm the flip-flop movement to be protein-mediated, based on its sensitivity to protease and protein-modifying reagents. To further determine the cellular localization of flippases, we isolated mitochondria of spermatozoa and checked for ATP-independent flippase activity. Interestingly, mitochondrial membranes showed flip-flop movement but were specific for PC with half-life time of $\sim 5 \pm 2 \mathrm{~min}$. Our results also suggest that spermatozoa have different populations of flippases and that their localization within the cellular compartments depends on the type of PL synthesis.

Reproduction (2013) 146 209-220
\end{abstract}

\section{Introduction}

Although lipid metabolism is well elucidated for somatic cells, it is not very clear for spermatozoa, which are differentiated cells. Spermatogenic differentiation is associated with distinct cellular and morphological changes. Each spermatozoon is composed of a head, a mid-piece containing stacked mitochondria, and a tail region. The head region contains the haploid chromatin and acrosome whereas the tail is made up of flagellum. Major organelles including endoplasmic reticulum (ER) are primarily lost during the development process while DNA synthesis, transcription, and translation are virtually nonexistent in spermatozoa; however, proteins involved in transcription and translation are abundantly present (Travis \& Kopf 2002, MartinezHeredia et al. 2006, Baker et al. 2007, de Mateo et al. 2007). One of the most significant changes observed during spermatogenesis are the changes in lipid composition. Phospholipids (PLs) have been shown to play an important role in intracellular signaling events in spermatozoa (Roldan \& Fragi 1993). Neutral lipids such as diacylglycerol (DAG) and ether lipids are present in unusually high proportions and a majority of PLs are composed of unsaturated fatty acids (22:6 and 22:5) (Gadella et al. 2008, Petcoff et al. 2008). Apart from this, mitochondria, the sole organelles of spermatozoa, are considered to be the energy source for sperm motility.

Sperm capacitation and fertilization are also associated with several cellular changes such as removal of sterols, increased plasma membrane (PM) fluidity, and elevation of intracellular $\mathrm{Ca}^{2+}$ (Jonge 2005). Spermatogonia, during initial stages of maturation, contain very high concentration of lipids, which may be either required for their differentiation or as substrates for ATP generation (Darin-Bennett et al. 1973). However, the demand for new PLs during differentiation exceeds the storage capacity, indicating that spermatozoa might have the ability to synthesize PLs on-site. Spermatozoal lysates were reported to synthesize cholesterol from acetate (Cross 1998, Izem \& Morton 2001), and 
ejaculated spermatozoa were shown to synthesize ether lipids that are usually abundant in sperm membranes (Jones 1997). Spermatozoa were able to incorporate radiolabeled precursors of palmitic acid, glycerol, choline, and arachidonic acid into DAG and phosphatidylcholine (PC), indicating that they possess active PL-synthesizing capability (Neill \& Masters 1972, Vasquez \& Roldan 1997). Despite this evidence, pathways as well as the site of PL synthesis remain unknown. The major impediment to studying PLs' metabolism is that spermatozoa do not survive for a long period under in vitro conditions. An earlier report has shown that spermatozoa are capable of mediating transbilayer movement of PLs in an ATP-dependant process using fluorescently labeled PLs and determined head group-specific flip-flop movement in live sperm cells by flow cytometry (Müller et al. 1994, Nolan et al. 1995). Another report showed transbilayer motion of spin-labeled PLs in sperm membrane preparation from ram caput, cauda, and ejaculated fractions (Müller et al. 1997). In somatic cells, mitochondria are also a major site for synthesis of phosphatidylserine (PS) and phosphatidylethanolamine (PE) and no major PL-synthesizing enzymes are localized to the PM or cytosol (Dowhan 1997, Vance 2008). Spermatozoa contain a large number of mitochondria wrapped around the tails in the mid-piece, which are known to be the source of energy required for sperm motility. As mitochondria are also biogenic membranes in somatic cells (Gallet et al. 1999, Meer et al. 2008), we hypothesize that they might be equipped with biogenic flippases. To validate our hypothesis, we performed various biochemical assays to provide evidence for the presence of ATP-independent flippase activity in sperm membranes, which is generally localized in PL-synthesizing (biogenic) membranes.

\section{Materials and methods}

\section{Materials}

Egg PC (ePC), sodium dithionite, Janus Green B, calcein, diethyl pyrocarbonate (DEPC), bovine pancreatic trypsin, phenylglyoxal (PG), 4-(2-aminoethyl)benzenesulfonyl fluoride (AEBSF), N-ethylmaleimide (NEM), ULTROL-grade Triton X-100, the protein estimation kit (BCA kit), methyl- $\beta$-cyclodextrin, cholesterol, and protease inhibitor cocktail were obtained from Sigma. 1-Oleoyl-2-(12-(7-nitro-2-1,3-benzoxadiazol-4-yl)aminododecanoyl)-sn-glycero-3-phosphocholine (NBD-PC), 1-oleoyl-2-(12-((7-nitro-2-1,3-benzoxadiazole-4-yl)amino)lauroyl)-sn-glycero-3-phosphoserine (NBD-PS), 1-oleoyl-2(6-((7-nitro-2-1,3-benzoxadiazol-4-yl)amino)hexanoyl)-sn-glycero-3-(phospho-rac-(1-glycerol)) ammonium salt (NBD-PG), and 1-oleoyl-2-\{12-((7-nitro-2-1,3-benzoxadiazole-4-yl)amino)lauroyl\}-sn-glycero-3 phosphoethanolamine (NBD-PE) were purchased from Avanti Polar Lipids (Alabaster, AL, USA), and SM-2 biobeads was purchased from Bio-Rad Laboratories. All other chemicals were procured from Himedia (Mumbai, India).

\section{Preparation of cauda epididymal whole sperm cell fractions}

Briefly, cauda epididymides were carefully dissected from bovine testes and pricked with a needle and spermatozoa were allowed to swim into PBS buffer containing $10 \mathrm{mM}$ glucose at $37^{\circ} \mathrm{C}$. The released sperm suspension was centrifuged at $100 \mathrm{~g}$ for $2 \mathrm{~min}$ at $4{ }^{\circ} \mathrm{C}$. The pellet containing sedimented tissue fragments was discarded and supernatant centrifuged at $1500 \mathrm{~g}$ for $10 \mathrm{~min}$ at $4{ }^{\circ} \mathrm{C}$ to pellet spermatozoa (Nagdas et al. 2006, Chakrabarty et al. 2007). The pellets were washed twice in buffer containing $10 \mathrm{mM} \mathrm{HEPES} / \mathrm{NaOH}$ and $100 \mathrm{mM} \mathrm{NaCl}$ and resuspended in the same buffer. Samples were processed by the routine swim-up procedure using Ham's F-10 nutrient medium (Mehmood et al. 2009). Briefly, sperm pellets were incubated in the medium for $30 \mathrm{~min}$ at $37^{\circ} \mathrm{C}$, allowing the motile sperm to swim-up to the medium.

\section{Isolation of mitochondria from whole cell}

Mitochondria were isolated according to previously reported methods (Nagdas et al. 2006). In brief, the washed pellets were suspended in buffer containing $10 \mathrm{mM} \mathrm{HEPES} / \mathrm{NaOH}$, $100 \mathrm{mM} \mathrm{NaCl}$, and protease inhibitor cocktail $(1: 100(\mathrm{v} / \mathrm{v}))$. The suspension was then sonicated using a blunt probe three times at 10-s intervals with a Sartorius stedium labsonic sonicator at a medium power setting and centrifuged at $1500 \mathrm{~g}$ for $10 \mathrm{~min}$ at $4{ }^{\circ} \mathrm{C}$. The pellets were washed twice in the same buffer and sonicated again ten times at 20-s intervals to detach the mitochondria. The suspension was again centrifuged at $1000 \mathrm{~g}$ and the supernatant was mixed with one-third volume of a $20 \%$ sucrose solution and pelleted at $8800 \mathrm{~g}$ for $15 \mathrm{~min}$ at $4{ }^{\circ} \mathrm{C}$. The crude mitochondrial pellet was resuspended in buffer and homogenized in glass-Teflon homogenizer. This suspension containing crude mitochondria was further enriched by layering on a $1 / 1.5 \mathrm{M}$ sucrose density gradient at $80000 \mathrm{~g}$ for $1 \mathrm{~h}$ in a SW28 rotor (Beckman Coulter, Brea, CA, USA) and collected at $100000 \mathrm{~g}$.

\section{Purity of isolated fractions}

Mitochondria were stained by incubation with Janus Green B $(10 \mathrm{mg} / \mathrm{ml})$ at room temperature for $15 \mathrm{~min}$. Images were procured using a bright-field microscope (Nikon Eclipse Ti) at $40 \times$ magnification (Yang et al. 2007). The purity was also tested for mitochondrial marker cytochrome $c$ by western blot analysis. The Triton X-100 extracts (TEs) of whole cell and mitochondria were solubilized in SDS sample buffer at $95^{\circ} \mathrm{C}$ and analyzed on a $12 \%$ SDS-PAGE. The PVDF membrane was equilibrated in the transfer buffer and polypeptides were electrophoretically transferred from the gel. After complete transfer at $90 \mathrm{~V}$ for $90 \mathrm{~min}$, the membrane was incubated with primary antibody (1:500 cytochrome $c$ ) at room temperature for $4 \mathrm{~h}$. The blot was washed and incubated with secondary antibody $(1: 2500)$ for $1 \mathrm{~h}$ and washed with buffer. The film was then developed in the dark room (Ott et al. 2002). The major contaminant in isolation of mitochondria from cells is PM and its contamination was checked using a PM ATPase assay (Bunney et al. 2001). The ATPase activity was measured in 
$50 \mathrm{mM} \mathrm{MES,} 10 \mathrm{mM} \mathrm{MgSO} 4 \cdot 7 \mathrm{H}_{2} \mathrm{O}, 5 \mathrm{mM}$ sodium azide, $0.2 \mathrm{mM}$ ammonium molybdate, $100 \mathrm{mM} \mathrm{KNO}_{3}$ and $3 \mathrm{mM}$ ATP in the presence and absence of $100 \mu \mathrm{M}$ sodium orthovanadate, which is a PM ATPase inhibitor. The activity was measured by the amount of phosphate released by ATP hydrolysis.

\section{Preparation of TE of whole spermatozoa and isolated mitochondria}

TE was prepared by adding $250 \mu$ l of isolated bovine spermatozoa and mitochondria to an equal volume of $2 \times$ reconstitution buffer $(10 \mathrm{mM}$ HEPES/NaOH, pH 7.5, $100 \mathrm{mM}$ $\mathrm{NaCl}$, and $1 \%(\mathrm{w} / \mathrm{v})$ Triton $\mathrm{X}-100)$ respectively. The sample was mixed and incubated at $4{ }^{\circ} \mathrm{C}$ with end-over-end rocking for $1 \mathrm{~h}$. It was then ultracentrifuged in a MLA 130 rotor at $175000 \mathrm{~g}$ for $30 \mathrm{~min}$ at $4{ }^{\circ} \mathrm{C}$ (Rajasekharan \& Gummadi 2011). The supernatant was carefully removed and used directly for reconstitution at a protein concentration of $\sim 3 \mathrm{mg} / \mathrm{ml}$.

\section{Reconstitution of liposomes and proteoliposomes}

Liposomes and proteoliposomes were prepared as described previously (Chang et al. 2004, Sahu \& Gummadi 2008); $4.5 \mu \mathrm{mol}$ ePC and $0.3 \mathrm{~mol} \%$ of labeled lipids such as NBD-PC, NBD-PS, NBD-PG, and NBD-PE were dried under a stream of nitrogen and solubilized in reconstitution buffer. For preparation of proteoliposomes, TE $(\sim 3 \mathrm{mg} / \mathrm{ml})$ was added to solubilized lipid samples with known protein concentration. Pretreated SM2 biobeads were used to remove Triton X-100 to form liposomes or proteoliposomes. The reconstituted liposomes and proteoliposomes were collected by ultracentrifugation in a MLA 130 rotor at $230000 \mathrm{~g}$ for $45 \mathrm{~min}$ at $4{ }^{\circ} \mathrm{C}$ and washed three to four times with assay buffer $(10 \mathrm{mM} \mathrm{HEPES} / \mathrm{NaOH}, \mathrm{pH} 7.5$, and $100 \mathrm{mM} \mathrm{NaCl}$ ) to remove background fluorescence due to nonreconstituted lipids and proteins. The vesicles were resuspended in $1 \mathrm{ml}$ of the same buffer and passed 11 times through a $0.1 \mu \mathrm{m}$ polycarbonate membrane filter using a lipid extruder to obtain vesicles of uniform size. The protein:PL ratio (PPR) of proteoliposomes was determined as described previously (Bligh \& Dyer 1959, Kaplan \& Pedersen 1989).

\section{Vesicle size analysis by dynamic light scattering}

The particle size (average mean diameter) of liposomes and proteoliposomes was measured by dynamic light scattering (DLS) at an angle of $90^{\circ}$ at $25^{\circ} \mathrm{C}$ for 5 min in a Microtrack particle analyzer. Diluted liposomes and proteoliposomes $(2.5 \mathrm{ml})$ were analyzed before and after extruding through a $0.1 \mu \mathrm{m}$ membrane filter.

\section{Sucrose flotation gradient analysis}

This experiment was performed to verify the reconstitution of membrane proteins from TE as described previously (Rigaud et al. 1988, Rajasekharan \& Gummadi 2011). Briefly, $1 \mathrm{ml}$ of the reconstituted proteoliposomes was layered on a series of sucrose $(\mathrm{w} / \mathrm{w})(20,10,5$, and $2.5 \%)$ and centrifuged at $100000 \mathrm{~g}$ in a swing-out rotor (SW 41Ti) for $1 \mathrm{~h}$. Fractions were collected from different sucrose interfaces and dialyzed against assay buffer for $24 \mathrm{~h}$ with three to four buffer changes to remove sucrose from the fractions. The amount of protein and PLs in the fractions was estimated as described previously (Bligh \& Dyer 1959, Kaplan \& Pedersen 1989).

\section{Collisional quenching experiments}

To confirm the steady-state distribution of the NBD-PLs across the membranes of liposomes and proteoliposomes, collisional quenching of NBD probe with potassium iodide $(\mathrm{KI})$ was performed according to the method reported previously (Vehring et al. 2007). NBD-PC containing liposomes and proteoliposomes was reconstituted using reconstitution buffer supplemented with $0.3 \mathrm{M} \mathrm{KCl}$. Excitation and emission wavelengths were set at 470 and $530 \mathrm{~nm}$ respectively. Fluorescence intensity was measured for samples consisting $50 \mu \mathrm{l}$ of vesicles diluted into $1.95 \mathrm{ml}$ of buffer containing $10 \mathrm{mM}$ HEPES/NaOH $(\mathrm{pH} 7.5)$ and the quencher $\mathrm{KI}(0-0.3 \mathrm{M})$. Data were analyzed according to the modified Stern-Volmer equation:

$$
F_{0} / \Delta F=\left(1 / f_{a}-K[Q]\right)+\left(1 / f_{a}\right)
$$

where $F_{0}$ is the fluorescence intensity in the absence of the quencher, $\Delta F$ is the fluorescence intensity in the presence of the quencher at concentration $[Q], f_{a}$ is the fraction of fluorescence that is accessible to the quencher, and $K$ is the Stern-Volmer quenching constant (Lakowicz 2006). The fraction of NBD-PC accessible to iodide quenching is calculated as the inverse of the $y$-intercept.

\section{Flippase assay}

The assay was performed using Perkin Elmer LS-55 Fluorescence Spectrophotometer as reported previously (Sahu \& Gummadi 2008, Rajasekharan \& Gummadi 2011). A total of $50 \mu \mathrm{l}$ of labeled liposomes and proteoliposomes were added to $1.95 \mathrm{ml}$ of assay buffer in a fluorescence cuvette. Timedependent fluorescence (excitation at $470 \mathrm{~nm}$ and emission at $530 \mathrm{~nm}$ ) was monitored with constant low-speed stirring at $25{ }^{\circ} \mathrm{C}$. After the stabilization of fluorescence intensity ( $200 \mathrm{~s}$ ), sodium dithionite (1 M prepared freshly in Tris base, $\mathrm{pH} 10.0$ ) was added to a final concentration of $2 \mathrm{mM}$ and the decrease in fluorescence was measured for $\sim 400 \mathrm{~s}$. The activity of flippase in a proteoliposome preparation was taken as the difference between the percentage reduced in the sample and the percentage reduced in a liposome sample (control). Briefly,

$$
P_{\text {red }}=\left(1-\frac{F_{t}}{F_{0}}\right) \times 100,
$$

where $F_{0}$ is the initial fluorescence, $F_{t}$ is the fluorescence intensity after dithionite reduction, and $P_{\text {red }}$ is the percentage of NBD-PC reduced.

$$
\text { Flippase activity }(A)=\left(P_{\text {red, proteoliposomes }}-P_{\text {red, liposomes }}\right) \text {. }
$$

\section{Protease/trypsin treatment}

Bovine pancreatic trypsin from a stock solution $(50 \mathrm{mg} / \mathrm{ml})$ was added to TE to yield a final concentration of $10 \mathrm{mg} / \mathrm{ml}$ and incubated at $37^{\circ} \mathrm{C}$ for $30 \mathrm{~min}$ before reconstitution. 
Similarly, the intact vesicles were treated with trypsin as described previously (Sahu \& Gummadi 2008). Briefly, $50 \mu \mathrm{l}$ liposomes (control) or proteoliposomes were added with desired final concentration of trypsin in assay buffer in a $200 \mu \mathrm{l}$ reaction mixture. The mix was incubated at $37^{\circ} \mathrm{C}$ for 30 min after which it was added to $2 \mathrm{ml}$ of assay buffer, and the fluorescence intensity was monitored as described previously.

\section{Effect of protein modification reagents on flippase activity}

Freshly prepared stock solutions (typically $100 \mathrm{mM}$ ) of DEPC in water, NEM, PG, and AEBSF in assay buffer were added to the liposomes (control) or proteoliposomes to yield the desired final concentration of protein-modifying reagent. After determining the effective working concentrations of these reagents, proteoliposomes with a known quantity of protein were used to study the effect of these compounds on flippase activity. TE was also treated with the highest concentration of protein modifiers, $20 \mathrm{mM}$ DEPC, $40 \mathrm{mM}$ NEM, $5 \mathrm{mM} \mathrm{AEBSF}$, and $5 \mathrm{mM}$ PG. The proportion of functional flippases eliminated by treatment with protein-modifying reagents (\% inhibition) was calculated from the percentage change in $P_{\text {red }}$ after subtracting $P_{\text {red }}$ for liposomes (Chang et al. 2004):

Percentage inhibition $=\left(1-\left(A_{\frac{\text { protein-modifying reagent }}{A_{\text {mock }}}}\right)\right) \times 100 \%$.

\section{Methyl- $\beta$-cyclodextrin treatment}

Many reports have shown that exposing cells to $\beta$-cyclodextrin results in solubilization and removal of cellular cholesterol, and it is widely used in cell culture experiments for the same purpose (Yancey et al. 1996, Eckford \& Sharom 2008). To check whether flippase activity is restored after cholesterol removal, we treated whole sperm cell and mitochondrial proteoliposomes reconstituted with $15 \mathrm{~mol} \%$ cholesterol using $20 \mathrm{mM}$ methyl- $\beta$-cyclodextrin. The sample was incubated at $37{ }^{\circ} \mathrm{C}$ for $1 \mathrm{~h}$. Proteoliposomes were collected by centrifugation and resuspended in fresh assay buffer. After two washes, the sample was checked for flippase activity as described in the earlier section.

\section{Statistical analysis}

Data are presented as the mean \pm s.D. Data were fitted to appropriate equations with $R^{2}>0.95$. For half-time calculations, initial fluorescence $\left(F_{0}\right)$ was taken as the average value of fluorescence intensity of the first plateau and the fluorescence after dithionite reduction $\left(F_{t}\right)$ was taken as the average value of the second plateau. The percentage of NBD lipids reduced $\left(P_{\text {red }}\right)$ upon dithionite addition was calculated by normalizing the $F_{0}$ to 1.0 and $F_{t}$ as a fraction of $F_{0}$, the difference between the percentage reduced in the proteoliposomes sample (test) and in a liposome sample (control) was considered to be activity. We used paired Student's $t$-test to assess differences between the fluorescence intensity (variable) using Prism 3.0 software (GraphPad, San Diego, CA, USA) with Cls set at $95 \%$. Probability values $(P)<0.05$ were considered to be statistically significant.

\section{Results}

\section{Isolation of sperm cells from bovine samples}

We isolated sperm cells from bovine cauda epididymides as described earlier. The purity of the isolated spermatozoa was confirmed by performing the 'swimup' experiment, which separates the active and motile cells. The isolated fractions were observed using a brightfield microscope and were found to be motile.

\section{Validation of reconstitution and vesicle integrity}

Liposomes and proteoliposomes from TE extract of whole sperm cells were generated as described earlier. To confirm that the TE proteins were reconstituted into vesicles, the proteoliposomes were fractionated on a sucrose flotation gradient. The results obtained showed that $\sim 50-55 \%$ of the protein and PL was recovered at the $10-20 \%(\mathrm{w} / \mathrm{v})$ sucrose interface (Fig. 1A). Analysis of the collisional quenching data using the modified SternVolmer plot indicated that $\sim 52 \pm 2$ and $\sim 56 \pm 3 \%$ of symmetrically labeled NBD-PC liposomes and proteoliposomes were accessible to iodide ions (Fig. 1B), implying that the labeled lipids are symmetrically distributed across the membranes reconstituted by SM2 Bio-bead-assisted Triton X-100 removal and that this is not affected by the presence of membrane proteins. DLS measurements confirmed that the effective diameters of majority of liposomes and proteoliposomes were $100 \pm 20$ and $110 \pm 5 \mathrm{~nm}$ respectively (Fig. 1C and D). The vesicles were also analyzed before extrusion and the diameter was found to be $\sim 500 \mathrm{~nm}$ (data not shown). Vesicle leakage was checked using calcein. Liposomes/ proteoliposomes encapsulated with calcein did not show emission at $517 \mathrm{~nm}$ in the presence or absence of dithionite. Upon addition of $0.2 \%$ Triton X-100, the emission peak increased because the vesicles were rendered leaky (data not shown). This confirmed that the vesicles were intact.

\section{Biogenic membrane flippase activity in proteoliposomes reconstituted with TE of intact whole sperm cells}

Both liposomes and proteoliposomes generated from detergent extract of sperm cells were treated with dithionite. Liposomes showed only 50-55\% quenching and the kinetic data fit well to single exponential decay with half-life of $\sim 0.4 \pm 0.05$ min (Fig. 2A). Proteoliposomes generated by reconstituting TE of whole sperm membrane proteins showed biphasic kinetics and the percentage of dithionite quenching was $60-85 \%$ (Fig. 2B, trace b, C, and d). The half-life of first phase was $18 \pm 2 \mathrm{~s}$ and second phase was calculated to be $3.2 \pm 1 \mathrm{~min}$. These results suggested that the proteoliposomes generated from TE of whole sperm cells were capable of translocating PC and the activity 

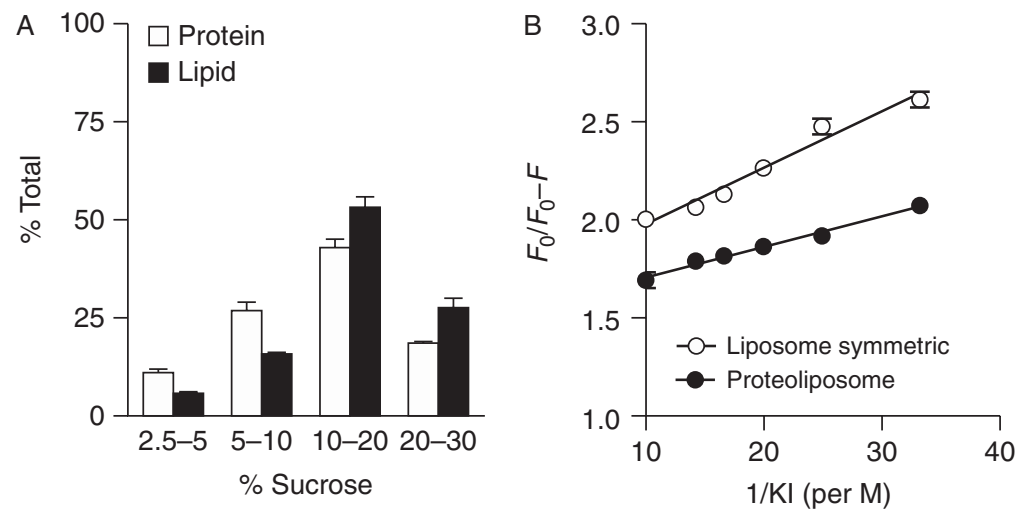

\begin{abstract}
Figure 1 Confirmation of vesicle integrity. (A) Sucrose flotation gradient analysis: the $x$-axis shows the interfaces between two sucrose step gradients and the $y$-axis shows the corresponding percentages of total lipid and protein at each interface. (B) Collisional quenching of NBD fluorescence with iodide ions was performed to determine the fraction of NBD-PC accessible on the outer leaflets of vesicles. Proteoliposomes (filled circles) and liposomes (open circles) were reconstituted from Triton X-100solubilized mixtures containing NBD-PC. The data are presented as modified Stern-Volmer plots, $F_{O}$ is the fluorescence intensity of the sample in the absence of quencher, whereas $\Delta F$ is the fluorescence intensity at a given iodide ion concentration. The inverse of the $y$-intercept represents the fraction of NBD-PC that is accessible to the quencher. Data were fitted to linear regression equation. The assay was performed two independent times and the $P$ value calculated was $<0.001$. (C and D) Liposomes and proteoliposomes were analyzed in a Microtrack particle analyzer. The DLS measurements showed liposomes (C) to be $100 \pm 20 \mathrm{~nm}$ and proteoliposomes (D) to be $110 \pm 5 \mathrm{~nm}$.
\end{abstract}

increased with increasing protein concentration in TE (Fig. 2B). To study the flippase activity as a function of protein concentration (TE extract), we generated proteoliposomes with varying amounts of protein and assayed for flippase activity. We found that, with the increase in TE addition during reconstitution, the amount of NBD quenching increases and eventually attains saturation at $\sim 350 \mathrm{mg} / \mathrm{mmol}$. Further increase in PPR did not show any improvement in percentage quenching (Fig. 2C). Whole sperm cell lipids were extracted and lipids corresponding to $100 \mu \mathrm{l}$ TE were reconstituted into liposomes and proteoliposomes. The presence of extracted lipids did not alter the quenching of PLs on the outer leaflet of liposomes and the kinetic data were fitted to a single exponential decay function (Fig. 2D). In order to check whether TE of the whole sperm cell can flip other PLs, we reconstituted NBD-labeled PS, PG, and $\mathrm{PE}$ into proteoliposomes and checked for flippase activity. We found that the flippases in whole cells were able to translocate PG and PS but not PE (Fig. 2E).

\section{Kinetics of NBD-PC flipping}

The first and second half-life time for all the experiments was calculated using the double exponential decay fit. Irrespective of the protein content in reconstituted vesicles, it was found that the first half-life time remained constant at $20 \pm 5 \mathrm{~s} \quad(0.4 \pm 0.05 \mathrm{~min})$ (Fig. 3A). The second half-life time of $6 \pm 1 \mathrm{~min}$ was constant till the PPR was $350 \mathrm{mg} / \mathrm{mmol}$. Beyond this level, the second half-life time decreased with an increase in PPR (Fig. 3B).

\section{Protease treatment and effect of protein modification on flippase activity}

To confirm that the second slow phase of decrease in fluorescence intensity is purely due to protein-mediated translocation, we treated the TE with trypsin $(10 \mathrm{mg} / \mathrm{ml}$ final concentration) prior to reconstitution and assayed for flippase activity. Consequently, vesicles generated from the trypsin-treated TE showed $\sim 55 \%$ activity similar to liposomes and the kinetics also fitted to single exponential decay fit (Fig. 4A, trace a - liposome, $\mathrm{b}$ - proteoliposome, and $\mathrm{c}-$ trypsin). This suggests that flippase activity was completely inhibited when TE was treated with trypsin and confirmed that PC flipping is protein mediated. In this study, we checked sensitivity of NBD-PC flipping to chemical modifications with various protein-modifying reagents as mentioned in the Materials and methods section. TE prior to reconstitution was treated and incubated for $30 \mathrm{~min}$ at $37^{\circ} \mathrm{C}$ and assayed for flippase activity. TE treated with modifiers showed that PC flipping was affected only upon AEBSF treatment (Fig. 4A, trace $\mathrm{d}-\mathrm{AEBSF}$ ). The other modifiers NEM (40 mM) and PG (5 mM) did not show any decrease or loss of activity beyond the concentrations (effective) used (Fig. 4A, traces e and $\mathrm{f}$ respectively). To have more insight into this, we also treated the proteoliposomes after reconstitution with varying concentrations of trypsin and AEBSF. The treated samples were then assayed for their ability to translocate NBD-PC. Trypsin treatment after reconstitution could not inhibit flippase activity, suggesting that the active sites of flippase 

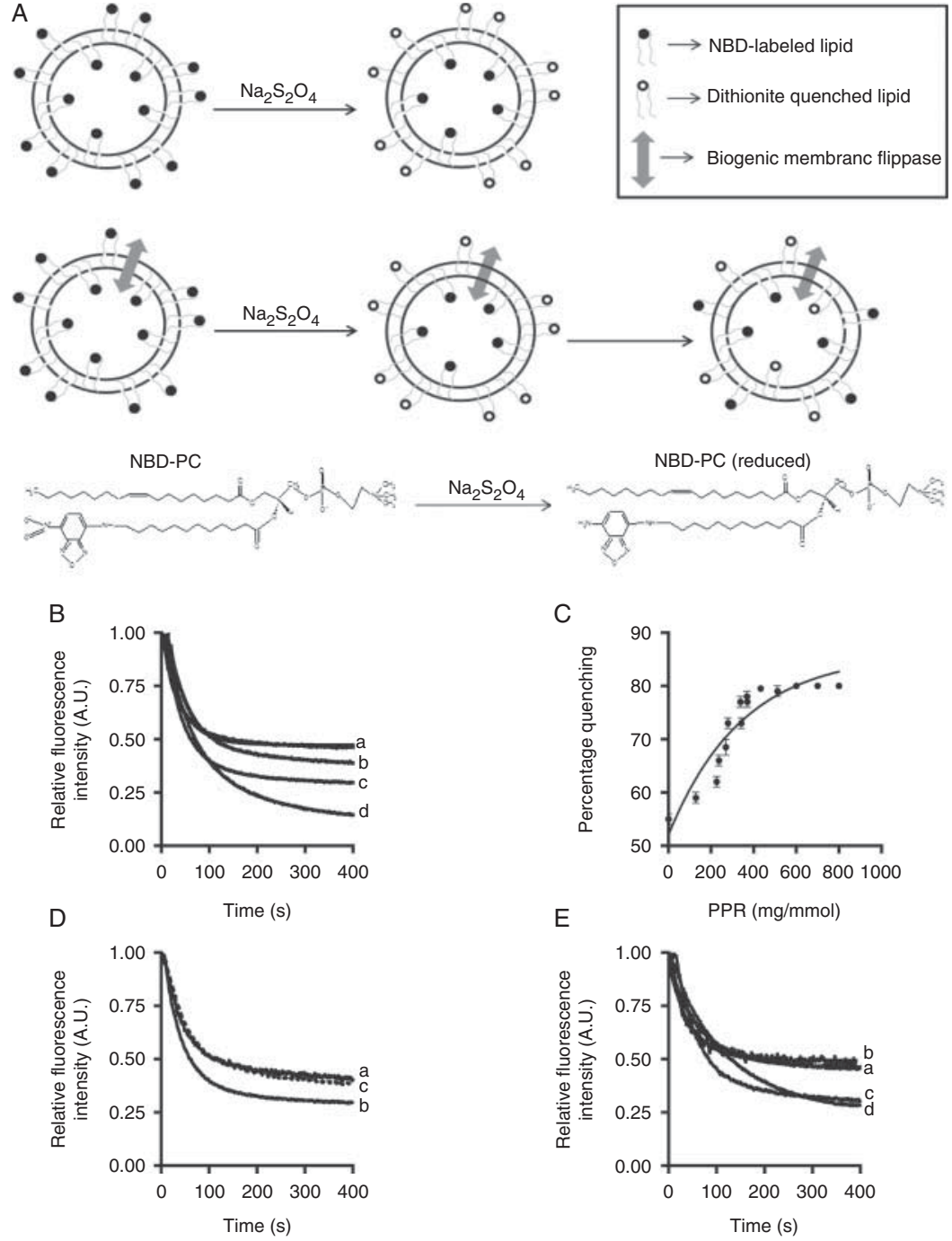

Figure 2 Biogenic membrane flippase activity in whole sperm cells. (A) Assay scheme: flippase activity is measured by quenching fluorescently labeled PLs by sodium dithionite. Reconstituted liposomes and proteoliposomes without flippase when treated with sodium dithionite, quenches $\sim 50-55 \%$ of the NBD-labeled PLs. In vesicles reconstituted with a functional flippase capable of bidirectional PL translocation, there is a second phase of slow quenching of NBD-labeled lipids to $>55-100 \%$. (B) The translocation of NBD-PC increases with an increase in the amount of protein in the proteoliposomes reconstituted with whole sperm cells (trace $\mathrm{a}$ - liposome, $\mathrm{b}-20 \mu \mathrm{lTE}, \mathrm{c}-40 \mu \mathrm{ITE}$, and d-200 $\mu \mathrm{l}$ TE) $(P<0.0001)$. (C) The extent of dithionite reduction of NBD-PC depends on PPR. Flippase activity increases proportionately with an increase in PPR and saturates at a PPR of $\sim 350 \mathrm{mg} / \mathrm{mmol}$. Above this value, the percentage of fluorescence quenching remains unchanged. The data were fitted to a mono exponential curve. (D) ePC supplemented with Bligh-Dyer lipid extract corresponding to $200 \mu \mathrm{ITE}$ did not show any flippase activity (trace a - liposome, $\mathrm{b}$ - proteoliposome, and c - lipid extract).

(E) Reconstitution of whole sperm TE with NBD-PS and NBD-PG showed flippase activity but NBD-PE did not show it (trace a - liposome, b - NBD-PE, $c-N B D-P S$, and d-NBD-PG). All the experiments were carried out three independent times. were buried inside the membrane bilayer during reconstitution and the kinetics was fitted to a double exponential decay equation (Fig. 4B, trace a - liposome, $\mathrm{b}$ - proteoliposome, $\mathrm{c}$ - trypsin-treated proteoliposome after reconstitution). AEBSF also did not show any inhibition after reconstitution, suggesting that the serine residues were buried inside (data not shown).

\section{Isolation of mitochondria and activity}

Mitochondria were isolated from whole sperm cells as described previously. Purity of the samples was confirmed by specifically staining the mitochondria both in the whole cell and in the isolated mitochondria as well as by western blot. Janus Green B, being an alkaline dye, is oxidized in the presence of cytochrome oxidase in the mitochondria forming a blue-green color. In Fig. 5A, the mid-piece of whole cell is stained blue-green and the right panel is the isolated mitochondria viewed under $40 \times$ bright-field microscope (Fig. 5B). Western blot analysis was performed for the isolated mitochondria and the supernatant containing contaminants, which is discarded during the isolation. The blot confirmed the purity of mitochondria as evident from the enhanced detection of cytochrome $c$ in the TE (Fig. 5C, 1). In order to check whether the mitochondrial membrane fractions isolated were contaminated with $\mathrm{PM}$, their being no other organelles present in sperms, we performed P-type ATPase assay in the presence and absence of vanadate, which is specific for PM. It was confirmed that the final pellet had the least ATPase activity (Fig. 5D).

\section{Biogenic membrane flippase activity in proteo- liposomes reconstituted with TE of mitochondria}

Mitochondrial membrane proteins were reconstituted into liposomes containing NBD-PC and these showed flippase activity with increasing protein concentration (Fig. 6A, trace a - liposome, b-100 $\mu \mathrm{lTE}$, and c-200 $\mu \mathrm{l}$ TE) but no activity was observed when reconstituted with PS or PG (Fig. 6B, traces $b$ and c). The flippase activity 

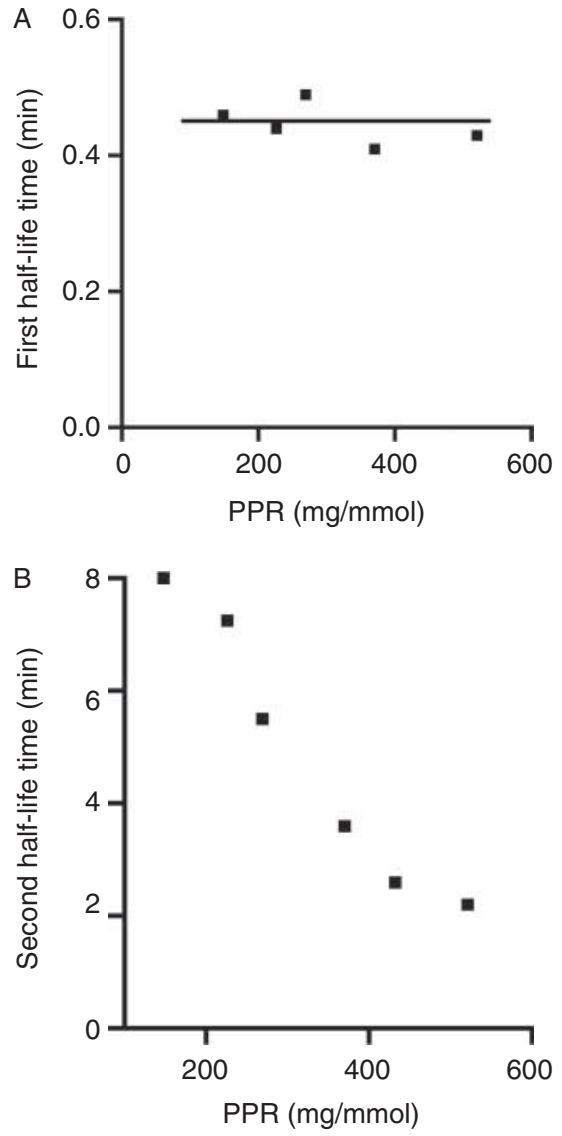

Figure 3 Kinetics of NBD-PC translocation by whole sperm TE. The calculation of half-life time was performed in GraphPad 3 Prism software using the equation $F(t)=F_{0}-\left(A_{1} \exp \left(-k_{1} t\right)+A_{2} \exp \left(-k_{2} t\right)\right.$, where $F(t)$ is the fluorescence as a function of time and $F_{0}$ is the fluorescence intensity at time $=0 \mathrm{~s}$ (i.e. initial fluorescence of the vesicles), $k_{1}$ and $k_{2}$ are the rate constants for the first (fast) and second (slow) phases respectively. $A_{1}$ and $A_{2}$ are the amplitudes of the fast and slow phases respectively. (A) The first phase half-life time remained constant at $0.4 \pm 0.05 \mathrm{~min}$, which represents the quenching of fluorescently labeled outer leaflet lipids. (B) The second phase half-life time decreased with an increase in PPR, suggesting that the kinetics of flipping increased and stabilized at a PPR of $\sim 350 \mathrm{mg} / \mathrm{mmol}$.

was confirmed to be protein-mediated by treatment of TE with trypsin and AEBSF before reconstitution. The activity dropped to $\sim 50 \%$ in both cases (Fig. $6 \mathrm{C}$, trace $\mathrm{b}$ and $\mathrm{c}$ ). The treatment of vesicles with trypsin and AEBSF after reconstitution did not show any significant inhibition of flippase activity (Fig. 6D, traces c and d).

\section{Effect of cholesterol}

Whole cell and mitochondrial TEs were reconstituted with $15 \mathrm{~mol} \%$ cholesterol. It was observed that whole cell activity was completely inhibited and was not restored even on treatment with $25 \mathrm{mM}$ cyclodextrin (Fig. 7A, traces $\mathrm{c}$ and $\mathrm{d}$ respectively). But when reconstituted with mitochondrial $\mathrm{TE}$, there was no inhibition of flippase activity (Fig. 7B).

\section{Discussion}

In eukaryotic somatic cells, ER, mitochondria, and Golgi complex are the major sites of lipid synthesis, with their active sites localized at the cytosolic leaflet (Voelker 1991, Meer et al. 2008). Newly synthesized lipids must be translocated across the bilayer for membrane growth and trafficked to other locations of the cell (Menon 1995, Gummadi \& Kumar 2005). Translocation or flip-flop movement of PLs is a thermodynamically unfavorable process because of the energy needed for moving the charged head groups of PL through the hydrophobic bilayer and this process is usually driven by metabolic energy. The $t_{1 / 2}$ of this translocation is in the order of hours to days (Rothman \& Kennedy 1977, Gummadi \& Kumar 2005). However, in biogenic membranes, $t_{1 / 2}$ of
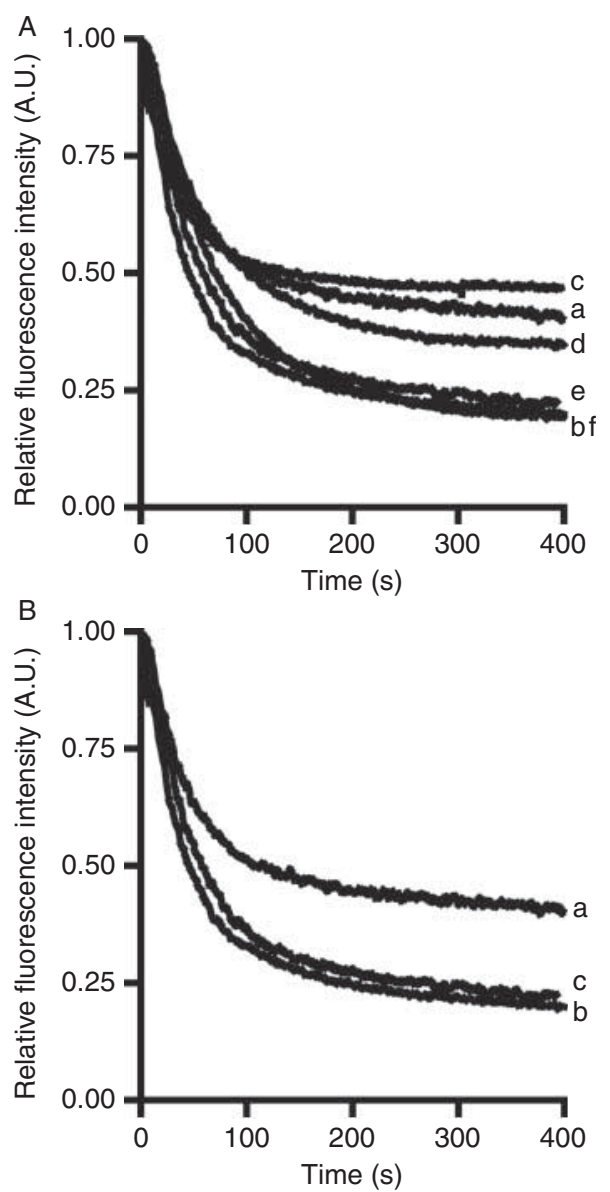

Figure 4 Effect of trypsin and protein-modifying reagents on flippase activity from whole sperm cell. (A) Treatment prior to reconstitution TEs were treated with $10 \mathrm{mg} / \mathrm{ml}$ trypsin and reconstituted (trace c). Traces $\mathrm{a}$ and $\mathrm{b}$ represent liposome and untreated proteoliposomes (control) $(P<0.0001)$. TE treated with protein-modifying reagents at working concentration showed inhibition only with AEBSF (trace d) while NEM (trace e) and PG (trace $f$ ) did not show any loss of activity $(P<0.001)$. (B) Trypsin treatment after reconstitution - proteoliposomes were incubated with trypsin, and flippase assay was carried out; traces $\mathrm{a}$ and $\mathrm{b}$ represent liposomes and untreated proteoliposomes respectively; trace c shows proteoliposomes treated with trypsin $(P<0.001)$. 
A

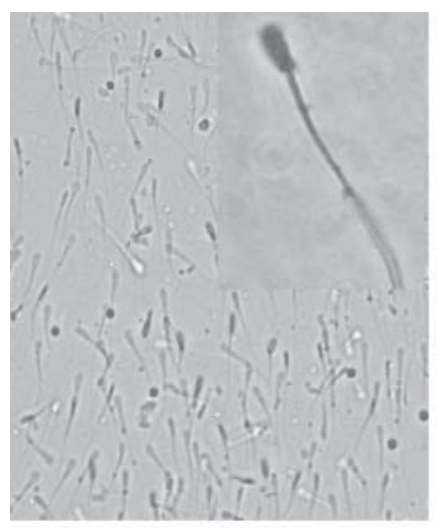

B

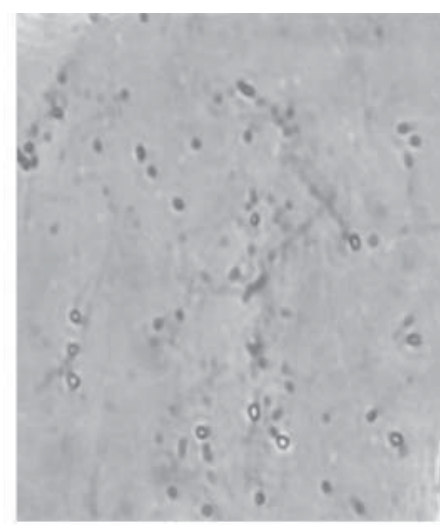

C 1

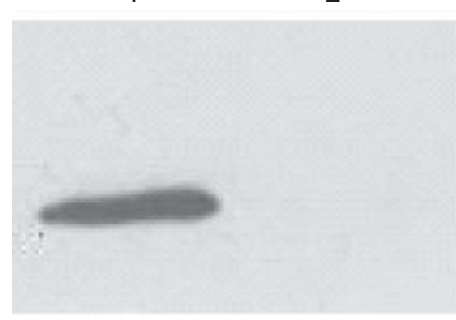

D

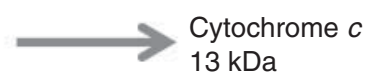

$13 \mathrm{kDa}$

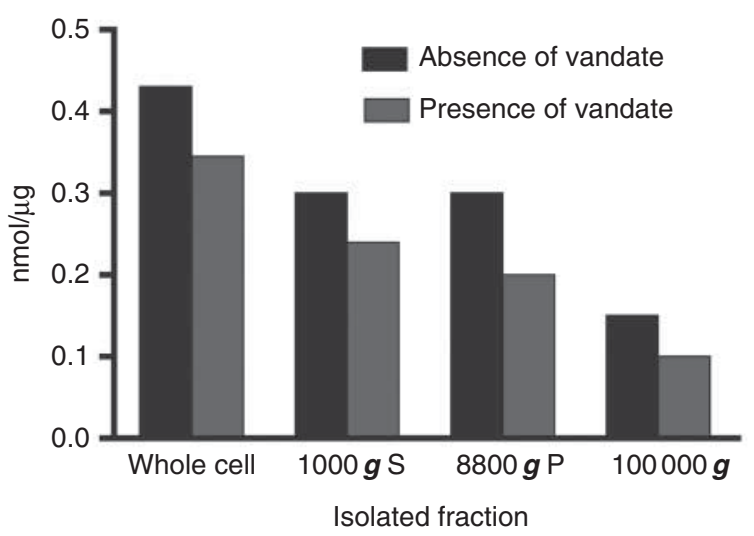

PL translocation was calculated to be in the order of few minutes with reports indicating their presence in ER, Golgi complex and chloroplasts (Bishop \& Bell 1985, Backer \& Dawidowicz 1987, Hrafnsdóttir et al. 1997, Menon et al. 2000, Gummadi \& Menon 2002, Kubelt et al. 2002, Chang et al. 2004, Rajasekharan \& Gummadi 2011). These biogenic membrane flippases are different from ATP-dependent flippases, which are involved in the maintenance of membrane asymmetry at PM (Holthuis \& Levine 2005, Pomorski \& Menon 2006).

As in the case of somatic cells, the sperm cell membrane lipid matrix is a heterogeneous mix of PLs, glycolipids, and sterols, which are distributed asymmetrically across the membrane leaflets (Apel-Paz et al. 2003). The PL distribution in PM of spermatozoa is asymmetric with PC present in the outer leaflet
Figure 5 Isolation of mitochondria from whole bovine sperm cells. (A) Micrograph of isolated spermatozoa (inset - bright-field image of whole cell spermatozoon viewed under $20 \times$ ) and (B) mitochondria stained with Janus Green B, which selectively stains the mitochondria. (C) Western blot of mitochondrial TE (lane 1) and supernatant obtained after centrifugation at $8800 \mathrm{~g}$ (lane 2) were probed with cytochrome $c$ $(13 \mathrm{kDa})$, a mitochondrial marker. (D) ATPase activity was measured as the amount of $P_{i}$ released by ATP in the presence and absence of sodium orthovanadate, a PM ATPase inhibitor was measured at $820 \mathrm{~nm}$. $\mathrm{S}$, supernatant, $\mathrm{P}$, pellet of the membrane, diphosphatidylglycerol and PS being localized predominantly to the inner monolayer (Hinkovska et al. 1986), and asymmetry in PM is maintained by the presence of ATP-dependent PL translocator in sperm PM (Müller et al. 1994, Nolan et al. 1995). However, there are no reports on the presence of biogenic membrane flippase activity in sperm cells. Previous reports suggested that lateral and horizontal transfer of lipids and proteins occur as well as membrane fluidity being altered during sperm passage through the epididymis. In boar spermatozoa during transit from epididymis, the membrane proportion of $\mathrm{PE}, \mathrm{PS}$, and phosphatidylinositol decreased along with an increase in the amount of PC, sphingomyelin, and polyphosphoinositides (Nikolopoulou et al. 1985, Reid et al. 2011). Based on these reports, we hypothesize 

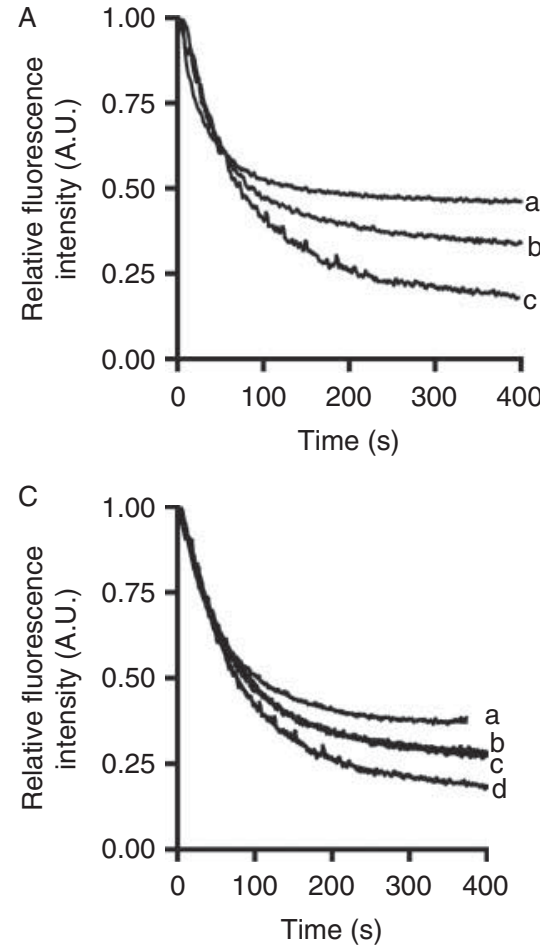
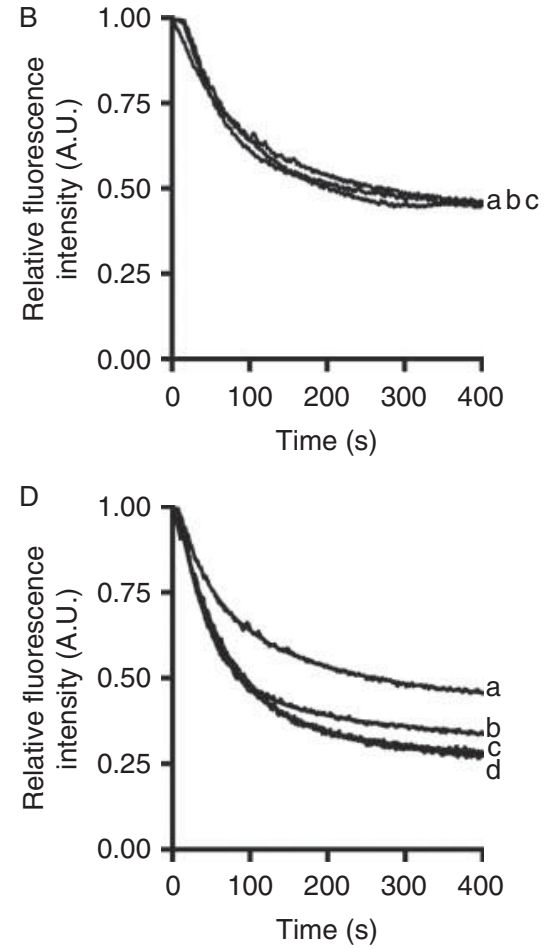

Figure 6 Biogenic membrane flippase activity (NBD-PC) in mitochondria is protein-mediated. (A) Mitochondrial TE reconstituted into proteoliposomes labeled with NBD-PC showed increasing activity with an increase in protein concentration (trace $\mathrm{a}$ - liposomes, trace $\mathrm{b}-100 \mu \mathrm{l}$ $\mathrm{TE}$, and trace $\mathrm{C}-200 \mu \mathrm{l})(P<0.0001)$. (B) No biogenic membrane flippase activity was observed when reconstituted with NBD-PS (trace b) or NBDPG (trace c) $(P<0.01)$. (C) Treatment with trypsin and AEBSF prior to reconstitution showed $\sim 50 \%$ inhibition of flippase activity (trace a - liposome, $\mathrm{b}$ - trypsin, $\mathrm{c}-\mathrm{AEBSF}$, and d - proteoliposomes (control) $(P<0.001)$. (D) Treatment after reconstitution by trypsin showed inhibition (trace c) but treatment with AEBSF (trace d) did not show any loss of activity. Traces a and b represent liposome and untreated proteoliposomes (control) respectively $(P<0.001)$. The experiments were carried out two independent times with assay in triplicates. that spermatozoa might have their own PL-synthesizing machinery to sustain during their membrane changes.

To confirm our hypothesis, we investigated the presence of biogenic flippase activity in whole spermatozoa as well as in mitochondria. As membrane proteins require a lipid environment for their functional activity, we used reconstituted proteoliposomes to characterize biogenic membrane flippase activity. Although reconstituted vesicles do not actually reflect the native membrane environment of sperm membranes, nevertheless functional activity of transmembrane-domaincontaining proteins has been successfully demonstrated in synthetic ePC vesicles (Vehring et al. 2007, Sahu \& Gummadi 2008, Menon et al. 2011). Sucrose flotation gradient analysis was performed to confirm protein incorporation into vesicles (Rigaud et al. 1988, Sahu \& Gummadi 2008). Protein and PL recovery in the reconstituted vesicles was $\sim 40$ and $\sim 80 \%$ respectively as reported by many groups following this protocol (Gummadi \& Menon 2002, Yang et al. 2007). In order to negate the effect of heterogeneous size of vesicles on contribution to flippase activity, vesicle size and distribution of PLs between the two leaflets were analyzed by DLS and collisional quenching experiments. Vesicle leakage caused due to reconstitution of membrane protein, and distinct packing conformation of various head group PLs was analyzed by calcein dye leakage assay (data not shown).

Flippase activity was measured by quenching the fluorescently labeled NBD-PLs using sodium dithionite, a membrane-impermeable reagent (Fig. 2A). Our results show that proteoliposomes generated from TE of whole spermatozoa were capable of translocating PC and an increase in activity was observed with increasing protein concentration in TE, suggesting that the activity is protein-mediated. The dose-response plot in Fig. 2B can be used to calculate the amount of flippases in the TE of spermatozoa membrane proteins. At the inflection point, i.e. $\sim 350 \mathrm{mg} / \mathrm{mmol}$, each vesicle is presumed to contain at least a single functional flippase. Preparations below $350 \mathrm{mg} / \mathrm{mmol}$ contain no or one flippase/vesicle and samples with $>350 \mathrm{mg} / \mathrm{mmol}$ contain one or more flippases/vesicle on an average. Previous studies on biogenic membrane flippases reported low saturation values for rat liver microsomes $(60 \mathrm{mg} / \mathrm{mmol})$, yeast (10 mg/mmol), Bacillus subtilis $(40 \mathrm{mg} / \mathrm{mmol})$, and spinach ER (40 mg/mmol) (Gummadi \& Menon 2002, Kubelt et al. 2002). The protein:PL saturation value obtained in this study was similar to that of spinach chloroplast membranes $(400 \mathrm{mg} / \mathrm{mmol})$. The high PPR saturation suggests that the amount of PC-translocating flippases is less and may depend on the physiological state of the cell. As biogenic membrane flippases are not head-groupspecific, we used other head group PLs such as PS, PG, and $P E$ and found that whole spermatozoa membranes were able to flip PC, PS, and PG (Fig. 2B and E).

Mitochondria isolated from spermatozoa showed flippase activity for only PC ( $\sim 5 \%$ quenching) similar to results described in a previous report which showed rapid $P C$ transbilayer movement in outer mitochondrial membrane isolated from rat liver (Dolis et al. 1996). Flip-flop movement of only PC occurring in an energyindependent manner can be attributed to the fact that PC forms the major lipid constituent of the mammalian 

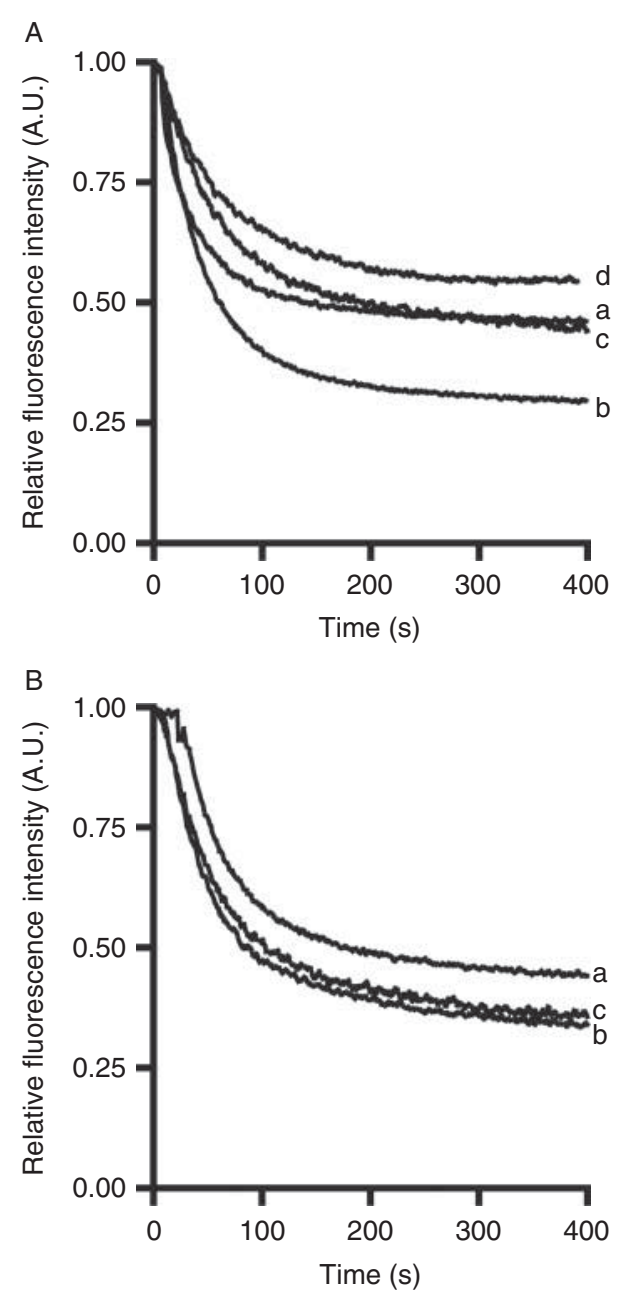

Figure 7 Effect of cholesterol on flippase activity. (A) Inhibition of flippase activity in proteoliposomes generated from TE of bovine whole sperm cells reconstituted with $15 \mathrm{~mol} \%$ cholesterol (trace c) $(P<0.001)$. Upon treatment of cholesterol-incorporated vesicles with $25 \mathrm{mM}$ cyclodextrin, activity was not restored (trace d). (B) Mitochondrial TE reconstituted with $15 \mathrm{~mol} \%$ cholesterol did not show any inhibition of flippase activity (trace a - liposome, trace $\mathrm{b}$ - proteoliposomes, and trace $\mathrm{c}-15 \mathrm{~mol} \%$ cholesterol $)(P<0.05)$. The experiments were carried out two independent times with assay in triplicates.

mitochondrial membrane. The transport of other head group PL in mitochondria might be an energy-dependent process, as the transbilayer movement of PE in rat liver mitoplasts was augmented twofold when the mitoplasts were energized (Gallet et al. 1999). Also, the protein complex involved in transport of other PLs would have disassociated during detergent extraction of mitochondrial membranes. But in somatic and yeast cells, the transbilayer movement of lipids is reported to be independent of their head group and a $t_{1 / 2}$ of 10-15 min was reported for spin-labeled PE, PC, and cardiolipin in purified beef heart mitochondrial inner membranes (Simbeni et al. 1990, Gallet et al. 1999).
As biogenic flippases are involved in rapid $\mathrm{PL}$ translocation to confirm that the flippase activity is protein-mediated, we treated proteins with trypsin and other modifying reagents before and after reconstitution. Protein modification studies are performed in a variety of membrane-localized transporters to identify amino acids that are vital for functionality of a protein. It has been widely reported that cysteine is a critical amino acid present in the class of flippases (Gummadi \& Menon 2002, Kubelt et al. 2002, Sahu \& Gummadi 2008). We used the common modifying reagents that included DEPC (His modifier), NEM (Cys modifier), AEBSF (Ser modifier), and PG (Arg modifier). Interestingly, NBD-PC flippase activity was not altered when either the proteoliposomes or TEs were treated with NEM, DEPC, and PG. But treatment of vesicles with AEBSF showed $\sim 50 \%$ loss of activity in both whole cells and mitochondria before reconstitution, confirming that the activity was protein-mediated and loss of activity was observed only upon treatment with serine modifier.

Membrane cholesterol is known to influence molecular packing and is present in high proportions in the epididymis where the stability and resilience of the membrane are most critical (Apel-Paz et al. 2003, 2005). Reports have shown that the presence of cholesterol in sperm cells prevents fusion and thereby leads to sterility. However, it is continuously removed from the membrane on arrival of spermatozoa in the female reproductive tract, in preparation for the fusion steps (Davis et al. 1979, Apel-Paz et al. 2003). We hypothesize that defective cholesterol removal mechanism might have led to the retention of cholesterol, which would have subsequently inhibited the flippases that modulate the sperm membranes. It has been reported that cholesterol inhibits flippase activity even at very low concentrations such as $1 \mathrm{~mol} \%$ (Rajasekharan \& Gummadi 2012). To check this effect, we reconstituted the whole cell and mitochondria with $15 \mathrm{~mol} \%$ cholesterol and our results confirmed that the presence of cholesterol inhibited flippase activity only in whole cells and not in mitochondria, which is consistent with earlier reports that have shown that spermatozoa continuously modulate membrane cholesterol content during their transport and maturation (Cross 1998, Apel-Paz et al. 2003).

In summary, we provide the first biochemical evidence, to our knowledge, for the existence of energy-independent biogenic membrane flippase activity in spermatozoa. Our results support the hypothesis that spermatozoa have the ability to synthesize PLs to sustain membrane modulations during their development and differentiation. The presence of a distinct flippase population in mitochondria specific for PC suggests that mitochondria alone may not contribute to the total lipid pool. Further molecular identification of flippases and lipid traffic is necessary to have more insight in understanding the mechanism of PL's flip-flop movement in an energy-independent manner. 


\section{Declaration of interest}

The authors declare that there is no conflict of interest that could be perceived as prejudicing the impartiality of the research reported.

\section{Funding}

This work was supported by a research grant from Department of Biotechnology, Government of India. V G Francis and A Rajasekharan were supported by Fellowship from the Council of Scientific and Industrial Research (CSIR) and Department of Biotechnology (DBT), Government of India, respectively.

\section{Acknowledgements}

The authors thank Prof. R S Verma for permitting them to use the bright-field microscope, Pavithra Shyamsunder for assistance in taking images (Biotechnology Dept, IIT Madras), and Debanjan Tewari for help with the western blot analysis (Biotechnology Dept, IIT Madras).

\section{References}

Apel-Paz M, Vanderlick TK, Chandra N \& Doncel GF 2003 A hierarchy of lipid constructs for the sperm plasma membrane. Biochemical and Biophysical Research Communications 309 724-732. (doi:10.1016/ j.bbrc.2003.08.065)

Apel-Paz M, Doncel GF \& Vanderlick TK 2005 Impact of membrane cholesterol content on the resistance of vesicles to surfactant attack. Langmuir: The ACS Journal of Surfaces and Colloids 21 9843-9849. (doi:10.1021/la050568r)

Backer JM \& Dawidowicz EA 1987 Reconstitution of a phospholipid flippase from rat liver microsomes. Nature 327 341-343. (doi:10.1038/327341a0)

Baker MA, Reeves G, Hetherington L, Muller J, Baur I \& Aitken RJ 2007 Identification of gene products present in Triton X-100 soluble and insoluble fractions of human spermatozoa lysates using LC-MS/MS analysis. Proteomics. Clinical Applications 1 524-532. (doi:10.1002/ prca.200601013)

Bishop WR \& Bell RM 1985 Assembly of the endoplasmic reticulum phospholipid bilayer: the phosphatidylcholine transporter. Cell $\mathbf{4 2}$ 51-60. (doi:10.1016/S0092-8674(85)80100-8)

Bligh EG \& Dyer WJ 1959 A rapid method of total lipid extraction and purification. Canadian Journal of Biochemistry and Physiology 37 911-917. (doi:10.1139/o59-099)

Bunney TD, Walraven HSV \& de Boer AH 2001 14-3-3 protein is a regulator of the mitochondrial and chloroplast ATP synthase. PNAS 98 4249-4254. (doi:10.1073/pnas.061437498)

Chakrabarty J, Banerjee D, Pal D, De J, Ghosh A \& Majumder GC 2007 Shedding off specific lipid constituents from sperm cell membrane during cryopreservation. Cryobiology 54 27-35. (doi:10.1016/j.cryobiol.2006. 10.191)

Chang Q, Gummadi SN \& Menon AK 2004 Chemical modification identifies two populations of glycerophospholipid flippase in rat liver ER. Biochemistry 43 10710-10718. (doi:10.1021/bi049063a)

Cross NL 1998 Role of cholesterol in sperm capacitation. Biology of Reproduction 59 7-11. (doi:10.1095/biolreprod59.1.7)

Darin-Bennett A, Poulos A \& White IG 1973 A re-examination of the role of phospholipids as energy substrates during incubation of ram spermatozoa. Journal of Reproduction and Fertility 34 543-546. (doi:10.1530/jrf.0.0340543)

Davis BR, Byrne R \& Hungund B 1979 Studies on the mechanism of capacitation. II. Evidence for lipid transfer between plasma membrane of rat sperm and serum albumin during capacitation in vitro. Biochimica et Biophysica Acta 558 257-266. (doi:10.1016/0005-2736(79)90260-8)
Dolis D, de Kroon AIPM \& de Kruijff B 1996 Transmembrane movement of phosphatidylcholine in mitochondrial outer membrane vesicles. Journal of Biological Chemistry 271 11879-11883. (doi:10.1074/jbc.271.20.11879)

Dowhan W 1997 Molecular basis for membrane phospholipid diversity: why are there so many phospholipids. Annual Reviews in Biochemistry 66 199-232. (doi:10.1146/annurev.biochem.66.1.199)

Eckford PDW \& Sharom FJ 2008 Interaction of the P-glycoprotein multidrug efflux pump with cholesterol: effects on ATPase activity, drug binding and transport. Biochemistry 47 13686-13698. (doi:10.1021/bi801409r)

Gadella BM, Tsai P, Boerke A \& Brewis IA 2008 Sperm head membrane reorganisation during capacitation. International Journal of Developmental Biology 52 473-480. (doi:10.1387/ijdb.082583bg)

Gallet FP, Zachowski A, Julien R, Fellmann P, Devaux PF \& Maftah A 1999 Transbilayer movement and distribution of spin-labelled phospholipids in the inner mitochondrial membrane. Biochimica et Biophysica Acta 1418 61-70. (doi:10.1016/S0005-2736(99)00022-X)

Gummadi SN \& Kumar KS 2005 The mystery of phospholipid flip-flop in biogenic membranes. Cellular \& Molecular Biology Letters 10 101-121.

Gummadi SN \& Menon AK 2002 Transbilayer movement of dipalmitoylphosphatidylcholine in proteoliposomes reconstituted from detergent extracts of endoplasmic reticulum: kinetics of transbilayer transport mediated by a single flippase and identification of protein fractions enriched in flippase activity. Journal of Biological Chemistry 277 25337-25343. (doi:10.1074/jbc.M203809200)

Hinkovska VT, Dimitrov GP \& Koumanov KS 1986 Phospholipid composition and phospholipid asymmetry of ram spermatozoa plasma membranes. International Journal of Biochemistry 12 1115-1121. (doi:10.1016/0020-711X(86)90085-6)

Holthius JCM \& Levine TP 2005 Lipid traffic: floppy drives and a superhighway. Nature Reviews Molecular Cell Biology 6 209-220. (doi:10.1038/nrm1591)

Hrafnsdóttir S, Nicholas JW \& Menon AK 1997 Transbilayer movement of fluorescent phospholipids in Bacillus megaterium membrane vesicles. Biochemistry 36 4969-4978. (doi:10.1021/bi962513h)

Izem L \& Morton RE 2001 Cholesteryl ester transfer protein biosynthesis and cellular cholesterol homeostasis are tightly interconnected. Journal of Biological Chemistry 276 26534-26541. (doi:10.1074/jbc. M103624200)

Jones RE 1997 Synthesis of ether lipids and phosphatidylethanolamine by ejaculated human spermatozoa. Archives of Andrology 38 181-189. (doi:10.3109/01485019708994876)

Jonge CD 2005 Biological basis for human capacitation. Human Reproduction Update 11 205-214. (doi:10.1093/humupd/dmi010)

Kaplan RS \& Pedersen PL 1989 Sensitive protein assay in the presence of high levels of lipid. Methods in Enzymology 172 393-399. (doi:10. 1016/S0076-6879(89)72025-5)

Kubelt J, Menon AK, Müller P \& Herrmann A 2002 Transbilayer movement of fluorescent phospholipid analogues in the cytoplasmic membrane of Escherichia coli. Biochemistry 41 5605-5612. (doi:10.1021/bi0118714)

Lakowicz JR 2006 Principles of fluorescence spectroscopy. Boston, MA, USA: Springer, Science and Business Media.

Martinez-Heredia J, Estanyol JM, Ballesca JL \& Oliva R 2006 Proteomic identification of human sperm proteins. Proteomics 6 4356-4369. (doi:10.1002/pmic.200600094)

de Mateo S, Martinez-Heredia J, Estanyol JM, Dominguez-Fandos D, Vidal-Taboada JM, Ballesca JL \& Oliva R 2007 Marked correlations in protein expression identified by proteomic analysis of human spermatozoa. Proteomics 7 4264-4277. (doi:10.1002/pmic.200700521)

Meer GV, Voelkar DR \& Feigenson GW 2008 Membrane lipids: where they are and how they behave. Nature Reviews. Molecular Cell Biology 9 112-124. (doi:10.1038/nrm2330)

Mehmood A, Anwar M \& Saqlan Naqvi SM 2009 Motility, acrosome integrity, membrane integrity and oocyte cleavage rate of sperm separated by swim-up or percoll gradient method from frozen-thawed buffalo semen. Animal Reproduction Science 111 141-148. (doi:10.1016/ j.anireprosci.2008.02.011)

Menon AK 1995 Flippases. Trends in Cell Biology 5 355-360. (doi:10.1016/ S0962-8924(00)89069-8)

Menon AK, Watkins WE \& Hrafnsdóttir S 2000 Specific proteins are required to translocate phosphatidylcholine bidirectionally across the endoplasmic reticulum. Current Biology 10 241-252. (doi:10.1016/ S0960-9822(00)00356-0) 
Menon I, Huber T, Sanyal S, Banerjee S, Barré P, Canis S, Warren JD, Hwa J, Sakmar TP \& Menon AK 2011 Opsin is a phospholipid flippase. Current Biology 21 149-153. (doi:10.1016/j.cub.2010.12.031)

Müller K, Pomorski T, Müller P, Zachowski A \& Herrmann A 1994 Protein-dependent translocation of aminophospholipids and asymmetric transbilayer distribution of phospholipids in the plasma membrane of ram sperm cell. Biochemistry 33 9968-9974. (doi:10.1021/bi00199a020)

Müller K, Müller P \& Herrmann A 1997 Transbilayer motion of spinlabelled phospholipids in the plasma membrane of epididymal and ejaculated ram spermatozoa. Journal of Reproduction and Fertility 111 81-89. (doi:10.1530/jrf.0.1110081)

Nagdas SK, Winfrey VP \& Olson GE 2006 Identification of a hamster sperm 26-kilodalton dehydrogenase/reductase that is exclusively localized to the mitochondria of the flagellum. Biology of Reproduction 75 197-202. (doi:10.1095/biolreprod.106.051375)

Neill AR \& Masters CJ 1972 Metabolism of fatty acids by bovine spermatozoa. Biochemical Journal 127 375-385.

Nikolopoulou M, Soucek DA \& Vary JC 1985 Changes in the lipid content of boar sperm plasma membranes during epididymal maturation. Biochimica et Biophysica Acta 3 486-498. (doi:10.1016/0005-2736 (85)90377-3)

Nolan JP, Magargee SF, Posner RG \& Hammerstedt RH 1995 Flow cytometric analysis of transmembrane phospholipid movement in bull sperm. Biochemistry 34 3907-3915. (doi:10.1021/bi00012a006)

Ott M, Robertson JD, Gogvadze V, Zhivotovsky B \& Orrenius S 2002 Cytochrome $c$ release from mitochondria proceeds by a two-step process. PNAS 99 1259-1263. (doi:10.1073/pnas.241655498)

Petcoff DW, Holland WL \& Stith BJ 2008 Lipid levels in sperm, eggs, and during fertilization in Xenopus laevis. Journal of Lipid Research 49 2365-2378. (doi:10.1194/jlr.M800159-JLR200)

Pomorski T \& Menon AK 2006 Lipid flippases and their biological functions. Cellular and Molecular Life Sciences 63 2908-2921. (doi:10.1007/ s00018-006-6167-7)

Rajasekharan A \& Gummadi SN 2011 Flip-flop of phospholipids in proteoliposomes reconstituted from detergent extract of chloroplast membranes: kinetics and phospholipid specificity. PLOS ONE 6 e28401. (doi:10.1371/journal.pone.0028401)

Rajasekharan A \& Gummadi SN 2012 Inhibition of biogenic membrane flippase activity in reconstituted ER proteoliposomes in the presence of low cholesterol levels. Cellular \& Molecular Biology Letters 17 136-152. (doi:10.2478/s11658-011-0042-8)

Reid AT, Redgrove K, Aitken RJ \& Nixon B 2011 Cellular mechanisms regulating sperm-zona pellucida interaction. Asian Journal of Andrology 13 88-96. (doi:10.1038/aja.2010.74)

Rigaud JL, Paternose MT \& Bluzat A 1988 Mechanisms of membrane protein insertion into liposomes during reconstitution procedures involving use of detergents. 2. Incorporation of the light driven proton pump bacteriorhodopsin. Biochemistry 27 2677-2688. (doi:10.1021/ bi00408a007)
Roldan ERS \& Fragi C 1993 Phospholipase A2 activation and subsequent exocytosis in the $\mathrm{Ca}^{2+}$ /lonophore-induced acrosome reaction of ram spermatozoa. Journal of Biological Chemistry 268 13962-13970.

Rothman JE \& Kennedy EP 1977 Rapid transmembrane movement of newly synthesized phospholipids during membrane assembly. PNAS 74 1821-1825. (doi:10.1073/pnas.74.5.1821)

Sahu SK \& Gummadi SN 2008 Flippase activity in proteoliposomes reconstituted with Spinach oleracea endoplasmic reticulum membrane proteins: evidence of biogenic membrane flippase in plants. Biochemistry 47 10481-10490. (doi:10.1021/bi8014339)

Simbeni R, Paltauf F \& Daum G 1990 Intramitochondrial transfer of phospholipids in the yeast, Saccharomyces cerevisiae. Journal of Biological Chemistry 265 281-285.

Travis AJ \& Kopf GS 2002 The role of cholesterol efflux in regulating the fertilization potential of mammalian spermatozoa. Journal of Clinical Investigation 110 731-736. (doi:10.1172/JCI0216392)

Vance JE 2008 Thematic Review Series: Glycerolipids. Phosphatidylserine and phosphatidylethanolamine in mammalian cells: two metabolically related aminophospholipids. Journal of Lipid Research 49 1377-1387. (doi:10.1194/jlr.R700020-JLR200)

Vasquez JM \& Roldan ERS 1997 Phospholipid metabolism in boar spermatozoa and role of diacylglycerol species in the de novo formation of phosphatidylcholine. Molecular Reproduction \& Development 47 105-112. (doi:10.1002/(SICI)1098-2795(199705)47:1<105:: AID-MRD14> 3.0.CO;2-0)

Vehring S, Pakkiri L, Schröer A, Alder-Baerens N, Herrmann A, Menon AK \& Pomoroski T 2007 Flip-Flop of fluorescently labeled phospholipids in proteoliposomes reconstituted with Saccharomyces cerevisiae microsomal proteins. Eukaryotic Cell 6 1625-1634. (doi:10.1128/EC.00198-07)

Voelker DR 1991 Organelle biogenesis and intracellular lipid transport in eukaryotes. Microbiological Reviews 55 543-560.

Yancey PG, Rodrigueza WV, Kilsdonk EPC, Stoudt GW, Johnson WJ, Phillips MC \& Rothblat GH 1996 Cellular cholesterol efflux mediated by cyclodextrins. Journal of Biological Chemistry 271 16026-16034. (doi:10.1074/jbc.271.27.16026)

Yang J, Ma L, Zhang Y, Fang F \& Li L 2007 Flow cytometric identification of two different rhodamine-123-stained mitochondrial populations in maize leaves. Protoplasma 231 249-252. (doi:10.1007/s00709-0070259-6)

Received 3 April 2013

First decision 29 April 2013

Revised manuscript received 13 June 2013

Accepted 18 June 2013 